\title{
O estado da arte sobre o uso de resíduos como matérias-primas cerâmicas alternativas
}

\author{
Romualdo R. Menezes ${ }^{1}$, Gelmires de A. Neves ${ }^{1}$ \& Heber C. Ferreira ${ }^{1}$ \\ 1 UFCG/DEMa. Rua Aprígio Veloso, 882, Bodocongó, CEP 58.109-970, Campina Grande, PB. Fone: (83) 310-1183, \\ Fax: (83) 310-1180. E-mail: gelmires@dema.ufpb.br (Foto) e heber@dema.ufpb.br \\ Protocolo $116-31 / 7 / 2001$
}

\begin{abstract}
Resumo: Os resíduos industriais e urbanos vêm-se tornando um dos mais sérios problemas que a sociedade moderna enfrenta. Sua deposição de forma inadequada provoca a degradação do meio ambiente e a contaminação dos mananciais de água e do solo. Por outro lado, técnicos da indústria cerâmica se deparam com a escassez de reservas de matérias-primas de boa qualidade em locais economicamente viáveis de exploração. Assim, este trabalho objetiva apresentar uma visão geral da possibilidade de utilização dos resíduos industriais e urbanos como matériasprimas cerâmicas alternativas, enfocando a indústria cerâmica como uma fonte economicamente viável e ecologicamente correta para reciclagem de resíduos.
\end{abstract}

Palavras-chave: reciclagem, resíduos, matérias-primas, indústria cerâmica

\section{State of the art about the use of wastes as alternative to ceramic raw materials}

\begin{abstract}
The industrial and urban wastes have become one of the most serious problems faced by the modern society. These wastes cause environmental degradation, with pollution and contamination of water and soil. On the other hand, the ceramic industry faces scarcity of good quality raw materials in locations close to the industries. The aim of this work is to give an overview about the possibility to use industrial and urban wastes as alternative to ceramic raw materials, focusing the use in ceramic industry as an economical and environmentally safe alternative for recycling wastes.
\end{abstract}

Key words: recycle, wastes, raw materials, ceramic industry

\section{INTRODUÇÃO}

Reciclagem é o conjunto das técnicas cuja finalidade é aproveitar detritos e rejeitos e reintroduzi-los no ciclo de produção. A reciclagem de resíduos, independentemente do seu tipo, apresenta várias vantagens em relação à utilização de recursos naturais "virgens", dentre as quais se tem: redução do volume de extração de matérias-primas, redução do consumo de energia, menores emissões de poluentes e melhoria da saúde e segurança da população. A vantagem mais visível da reciclagem é a preservação dos recursos naturais, prolongando sua vida útil e reduzindo a destruição da paisagem, fauna e flora.

Nos últimos anos, a pesquisa sobre a reciclagem de resíduos industriais vem sendo intensificada em todo o mundo. $\mathrm{Na}$ América do Norte e Europa, a reciclagem é vista, pela iniciativa privada, como um mercado altamente rentável. Muitas empresas investem em pesquisa e tecnologia, o que aumenta a qualidade do produto reciclado e propicia maior eficiência do sistema produtivo. Paralelamente, a reciclagem de resíduos urbanos ganha evidência, em virtude do crescente volume de rejeitos sólidos e da indisponibilidade cada dia maior de locais para descarte desse material, em particular em grandes centros urbanos, com elevada densidade demográfica.

No Brasil, diversos pesquisadores têm-se dedicado ao estudo desse tema, obtendo-se resultados bastante relevantes; todavia, a reciclagem ainda não faz parte da cultura dos empresários e cidadãos. A reciclagem de resíduos industriais ainda possui índices insignificantes frente ao montante produzido e, a cada dia, os rejeitos urbanos agridem mais o meio ambiente, em virtude da falta de tratamentos adequados e fiscalização sobre a manipulação e descarte desses rejeitos.

$\mathrm{O}$ aproveitamento dos rejeitos industriais para uso como materiais alternativos não é novo e tem dado certo em vários países do Primeiro Mundo, sendo três as principais razões que motivam os países a reciclarem seus rejeitos industriais; primeiro, o esgotamento das reservas de matérias-primas confiáveis; segundo, o crescente volume de resíduos sólidos, que põem em risco a saúde pública, ocupam o espaço e degradam os recursos naturais e, terceiro, a necessidade de compensar o desequilíbrio provocado pelas altas do petróleo. 
A indústria cerâmica é uma das que mais se destacam na reciclagem de resíduos industriais e urbanos, em virtude de possuir elevado volume de produção que possibilita o consumo de grandes quantidades de rejeitos e que, aliado às características físico-químicas das matérias-primas cerâmicas e às particularidades do processamento cerâmico, faz da indústria cerâmica como uma das grandes opções para a reciclagem de resíduos sólidos. Ademais, é uma das poucas áreas industriais que podem obter vantagens no seu processo produtivo com a incorporação de resíduos entre suas matérias-primas, a exemplo da economia de matérias-primas de elevada qualidade, cada dia mais escassas e caras, a diversificação da oferta de matériasprimas, e a redução do consumo de energia e, por conseguinte, redução de custos (Wender \& Baldo, 1998).

Vários são os resíduos industriais absorvidos pela indústria cerâmica, podendo-se citar os resíduos de mineração, da indústria do papel e celulose, metalúrgica, energética etc. que, independentemente de sua origem, têm utilização cada dia maior como matérias-primas alternativas na indústria cerâmica, enquanto praticamente todos os tipos de resíduos urbanos podem ser incorporados nas formulações cerâmicas após tratamento adequado. Assim, este trabalho tem por objetivo propiciar uma visão geral da indústria cerâmica como grande fonte sorvedora de resíduos industriais e urbanos, evidenciando seu papel de destaque na tecnologia da reciclagem atual.

\section{RESÍDUOS NA INDÚSTRIA CERÂMICA}

As massas utilizadas na indústria cerâmica tradicional são de natureza heterogênea, geralmente constituídas de materiais plásticos e não plásticos, com um vasto espectro de composições, motivo pelo qual permitem a presença de materiais residuais de vários tipos, mesmo em porcentagens significantes.

Desta forma, a reciclagem e a reutilização de resíduos provenientes de diferentes processos industriais, como novas matérias-primas cerâmicas, têm sido objeto de pesquisas em diversas instituições, que buscam soluções que conciliem vários aspectos, como custo de disposição, tratamentos, tipo e quantidade de resíduo, tecnologia e processos de utilização e, finalmente, o impacto econômico e ambiental da reciclagem.

De acordo com suas características e influência sobre as propriedades das formulações e corpos cerâmicos, pode-se agrupar os resíduos sólidos, quando absorvidos pela indústria cerâmica, em: redutores de plasticidade, fundentes, combustíveis, cinzas volantes, resíduos da incineração de rejeitos urbanos e radioativos, ressaltando-se que uma classificação sistemática dos resíduos é muito complexa, em virtude da grande variabilidade de suas propriedades e de sua influência nas formulações de corpos cerâmicos e, sendo assim, a classificação realizada nesse trabalho tem por intuito apenas facilitar a visualização e a abordagem do tema.

\section{Resíduos redutores de plasticidade}

Os resíduos redutores de plasticidade caracterizam-se por serem materiais friáveis que, quando adicionados às massas cerâmicas, provocam a redução de sua plasticidade; em geral, eles são provenientes das indústrias de mineração e beneficiamento mineral, apresentando composição química e granulométrica bastante variáveis, dependendo da origem dos materiais. As quantidades de resíduos incorporados às matrizes cerâmicas podem variar entre 10 e $60 \%$, provocando ligeiras mudanças nas propriedades mecânicas, retração e absorção de água (Sabrah et al., 1987).

Dentre esses resíduos pode-se citar: os da extração de ardósia, que se mostram adequados à produção de peças por colagem; os provenientes de esteatitos e pedra sabão, potencialmente utilizáveis na fabricação de revestimentos cerâmicos; os resíduos argilosos em geral, que podem compor a formulação de composições para a produção de telhas, tijolos e revestimentos cerâmicos (Wender \& Baldo, 1998). Com grande destaque, encontram-se os resíduos da mineração e beneficiamento das rochas graníticas, já tendo sido verificada sua aplicabilidade na produção de tijolos e revestimentos e na confecção de argamassas (Freire \& Motta, 1995; Raigón et al., 1996; Vieira et al., 1999; Neves et al., 2000).

Os resíduos da mineração e beneficiamento de rochas estão sendo largamente estudados em virtude do grande impacto ambiental provocado quando descartados indiscriminadamente na natureza e do enorme potencial que possuem como matériasprimas cerâmicas. Em geral esses resíduos são descartados em lagos, rios, faixas de domínio de rodovias e ao redor das mineradoras (ou empresas de beneficiamento) causando uma série de agressões à fauna e flora, bem como à saúde da população, principalmente quando se encontra em forma seca e pulverulenta.

A preocupação crescente com este tipo de resíduo baseiase também nos elevados índices de crescimento do setor mineral em todo o mundo, especialmente no que diz respeito às rochas ornamentais, fato que, aliado ao elevado desperdício do setor (que pode chegar a $50 \%$, em massa, do total produzido) gera um cenário altamente preocupante tanto para ambientalistas como para a sociedade em geral.

Este quadro de preocupação tem levado a se repensar a forma de utilização dos resíduos minerais nas formulações cerâmicas. Alguns anos atrás eram feitas pequenas adições às massas cerâmicas (em torno de 10 a 20\%); todavia, estas aplicações não eram suficientes para absorver as enormes quantidades de rejeito, passando alguns estudos (Raigón et al., 1996), principalmente na Europa, a analisar o uso de formulações compostas com elevado teor de resíduos (> 50\%) chegando a trabalharem com formulações compostas exclusivamente por resíduos. Neste ponto, é interessante ressaltar que os resíduos definidos aqui como redutores de plasticidade, não necessariamente atuam apenas reduzindo a plasticidade das massas cerâmicas, podendo atuar também como agentes formadores de fase vítrea, o que, em muitas aplicações, é um fator de grande influência no sucesso do uso desses resíduos na produção de tijolos, revestimentos, grés e produtos de baixa absorção de água (produtos com grande valor agregado) evidenciando-se que a fase vítrea formada pode atuar preenchendo os poros do material, ou como matriz vítrea ligante de grãos cristalinos. 
Até o momento, mostrou-se que os resíduos minerais compõem a maioria dos resíduos redutores de plasticidade; no entanto, alguns outros resíduos podem ser enquadrados nesse grupo, a exemplo de resíduos oriundos da própria indústria cerâmica (rejeitos de tijolos e revestimentos e peças com defeito) os quais são, em grande parte absorvidos pela própria indústria geradora, enquanto outros são utilizados em diversas indústrias, como a cimenteira. A própria indústria cimenteira é uma grande geradora de resíduos que, quando não coletados de maneira adequada podem provocar vários problemas respiratórios à população, sendo sua reutilização totalmente possível dentro do próprio processo produtivo ou em algum outro ramo cerâmico.

Outro resíduo que merece destaque e pode ser enquadrado como redutor de plasticidade é o resíduo de amianto, material que, por ser considerado cancerígeno, teve sua utilização abolida nas últimas décadas nos EUA, Europa e alguns países da Ásia, com os produtos contendo amianto tendo que passar por tratamentos que evitem seu contato com o ser humano. Dentre esses tratamentos, tem-se a sua utilização como matéria-prima cerâmica alternativa, sofrendo decomposição e reagindo com os demais constituintes da massa no decorrer da queima, transformando-se em materiais não nocivos à saúde, podendo ser utilizado na produção de cerâmicas tradicionais sem redução na qualidade do produto final (Gualtieri \& Tartaglia, 2000). No Brasil o amianto sofre algumas restrições, mas ainda é muito utilizado na produção de telhas e reservatórios de água.

O Centro de Ciências e Tecnologia da Universidade Federal de Campina Grande, através do Grupo de Estudo de Resíduos Sólidos (GEARES) formado por professores com formação multidisciplinar dos Departamentos de Engenharia de Materiais (DEMa), Engenharia Civil (DEC) e Engenharia Agrícola (DEAg), vem buscando dar sua contribuição à reciclagem de resíduos industriais, desenvolvendo pesquisas visando ao aproveitamento de resíduos minerais da região Nordeste, para utilização como insumos na obtenção de tijolos e blocos não queimados (com e sem função estrutural) na produção de argamassas de assentamento, de pedras ornamentais sintéticas, de tijolos e revestimentos cerâmicos e de grés sanitários, obtendo-se resultados satisfatórios (Neves et al., 2000).

A Tabela 1 apresenta características e propriedades de corpos cerâmicos à base de argila, com resíduos redutores de plasticidade. Observa-se que os valores das características cerâmicas são bastante variáveis e intimamente relacionados com o tipo de conformação e temperatura de queima. De forma geral, verifica-se que os teores de resíduo podem atingir níveis extremamente elevados (maiores que 50\%) e, mesmo assim, o corpo cerâmico apresenta características mecânicas adequadas para sua aplicação como tijolos (resistência superior a $5 \mathrm{MPa}$ ).

$\mathrm{Na}$ mesma tabela, verifica-se que as formulações são extremamente versáteis, já que, mesmo se fazendo uso de temperaturas de queima relativamente baixas obtêm-se produtos com características mecânicas adequadas às aplicações comerciais, evidenciando-se a possibilidade de se conseguir produtos "mais nobres", menor absorção de água e maior resistência, caso se utilizem temperaturas de queima mais elevadas.

Um ponto que não está evidenciado na Tabela 1, mas que merece ser mencionado, é a possibilidade de redução dos gastos energéticos do processamento cerâmico com a incorporação de resíduos do beneficiamento de minérios às formulações cerâmicas. Esses resíduos possuem, em geral, forma pulverulenta, o que elimina (ou diminui) a necessidade de processos prévios de cominuição do material, gerando uma sensível economia no processamento cerâmico, ao se analisálo como um conjunto de operações que se iniciam desde a extração e o beneficiamento das matérias-primas.

\section{Resíduos fundentes}

A principal característica dos resíduos fundentes é a de produzir diminuição na temperatura de maturação do corpo cerâmico, possibilitando redução do consumo energético, graças às novas características da massa cerâmica. Esses resíduos são, geralmente provenientes da lama de esmaltação das cerâmicas e dos rejeitos da indústria mecânica e metalúrgica e têm uma composição sílico-aluminosa $\left(\mathrm{SiO}_{2}+\mathrm{Al}_{2} \mathrm{O}_{3}>50 \%\right)$ com porcentagens variáveis de metais pesados (em alguns casos bem elevadas), alcalinos e alcalinos terrosos, com presença freqüente de $\mathrm{Cr}, \mathrm{Co}, \mathrm{Ni}, \mathrm{Cd}, \mathrm{Cu}, \mathrm{Zn}, \mathrm{Pb}$ etc.

A título de ilustração, tem-se a produção de "tijolos ecológicos" (Domínguez \& Ullmann, 1996) com argilas e resíduos da indústria do aço contaminados com $\mathrm{Zn}, \mathrm{Pb}, \mathrm{Cu}, \mathrm{Ni}$ e $\mathrm{Cr}$, havendo a neutralização dos agentes poluentes. Outros exemplos de estudos bem sucedidos são a utilização de rejeito de água de unidades de galvanização, de resíduos de escória de alto forno (Elwan \& Hassan, 1998) e de resíduos de aciaria na produção de tijolos, telhas, blocos e revestimentos cerâmicos, sendo atingida boa inertização dos agentes poluentes.

Tabela 1. Características e propriedades de corpos cerâmicos à base de argila, com resíduos redutores de plasticidade*

\begin{tabular}{|c|c|c|c|c|c|c|c|}
\hline \multirow[b]{2}{*}{ Características Cerâmicas } & \multicolumn{7}{|c|}{ Tipo de Resíduo } \\
\hline & $\begin{array}{l}\text { Pó de } \\
\text { Basalto }\end{array}$ & $\begin{array}{c}\text { Pó de } \\
\text { Granito }\end{array}$ & $\begin{array}{l}\text { Lama de } \\
\text { Chamota }\end{array}$ & $\begin{array}{c}\text { Pó de } \\
\text { Cimento }\end{array}$ & Dolomita & $\begin{array}{l}\text { Pó de } \\
\text { Rocha }\end{array}$ & $\begin{array}{l}\text { Chamota } \\
\text { Refratária }\end{array}$ \\
\hline Teor de resíduo $(\%)$ & $10-30$ & $20-50 \%$ & $20-60$ & $10-30$ & 10 & $10-100$ & $10-50$ \\
\hline Técnica de moldagem & Extrusão & Prensagem & Extrusão & Extrusão & Extrusão & Prensagem & Manual \\
\hline Resistência à flexão após secagem (MPa) & - & $2-6$ & - & - & $4-6$ & - & - \\
\hline Retração de secagem (\%) & $8-10$ & $0-2$ & $9-12$ & $10-11$ & $6-8$ & - & $7-8$ \\
\hline Temperatura de queima $\left({ }^{\circ} \mathrm{C}\right)$ & $900-1000$ & $800-1000$ & $900-1000$ & $900-1050$ & 980 & $1100-1200$ & $950-1000$ \\
\hline Absorção de água (\%) & $10-15$ & $7-22$ & $6-11$ & $17-25$ & $10-13$ & $0-4$ & $19-20$ \\
\hline Retração de queima (\%) & $1-2$ & $0-2$ & $3-6$ & $1-2$ & $0-1$ & - & $0-2$ \\
\hline Resistência à flexão após queima (MPa) & - & $2-14$ & - & - & $7-10$ & $30-90$ & $4-9$ \\
\hline
\end{tabular}

* Fonte: Vieira et al. (1999); Neves (2002) 
Neste sentido, é de extrema importância abordar a capacidade de inertização de metais pesados por parte dos materiais cerâmicos. Tecnologias envolvendo a transformação de resíduos em aglomerados cimentícios, em vidros ou vitrocerâmicos (vidro que, após fusão, sofre um processo de cristalização parcial) têm adquirido, a cada dia, mais importância econômica.

A imobilização em matrizes cimentícias, como, por exemplo, cimento Portland, não requer tratamentos térmicos para transformar resíduos nocivos em inertes imersos em uma matriz estável. O produto final é resistente a agentes ambientais agressivos e é usualmente aprovado nos ensaios de resistência a lixiviação, podendo por conseguinte ser depositado em aterros, de forma segura; entretanto, este processo vem experimentando uma crescente oposição em muitos países da comunidade européia, em virtude da estabilidade dos materiais cimentícios não estar definitivamente comprovada e, também, porque o volume da mistura cimentante é bem maior que o do resíduo, o que reduz a capacidade dos aterros, além do que a mistura com materiais nocivos nem sempre pode ser reutilizada na indústria da construção civil (Pelino, 2000).

Alternativamente, a tecnologia de cerâmicas cristalinas (neste sentido, entenda-se por materiais que sofreram um processo de queima, já que se está considerando o cimento como material cerâmico) e do vidro é considerada a mais versátil para a imobilização de resíduos nocivos à saúde, já que elas destroem a matéria orgânica, imobilizam metais pesados em uma matriz comprovadamente estável, com consistente redução do volume, e são capazes de converter composições químicas complexas em materiais usuais, com grande potencial de aplicação no mercado.

Esta tecnologia se baseia na incorporação na estrutura cristalina dos elementos presentes nos resíduos, seja por meio de solução sólida ou intersticial; na formação de fases vítreas que atuam como matriz estável, imobilizando outras fases, dentre essas as referentes aos resíduos, ou a total fusão do material com formação de um vidro estável à lixiviação ou às condições agressivas do meio. Particularmente, a vitrificação de resíduos nocivos é considerada um processo de estabilização ambientalmente correto, em virtude da grande resistência química dos produtos vítreos à maioria das condições ambientais, resistência esta relacionada ao fato dos componentes nocivos, essencialmente metais pesados, efetuarem ligações em nível atômico na estrutura do vidro (Pisciella et al., 2001). Neste enfoque, está centrada grande parte dos estudos dedicados à reciclagem de resíduos industriais e urbanos, sendo possível a produção de vidros e vidros-cerâmicos aplicados a uma série de usos comerciais, como vidrados, fibras de vidro, ligantes, pigmentos etc. Este tema será abordado novamente em cinzas volantes e resíduos urbanos.

Salienta-se que os resíduos fundentes apesar de diminuírem a temperatura de maturação dos corpos cerâmicos, não necessariamente por si só, possibilitam uma adequada maturação do corpo (Montano et al., 2001) ou a formação de vidros com características adequadas ao processamento cerâmico. Na maioria dos casos a formulação de composições para obtenção de vidros e vitrocerâmicos, dentro das características do processamento cerâmico, utiliza algumas outras matérias-primas, tais como, areia, calcário e até mesmo outros tipos de resíduos, como os da indústria do vidro (que, dependendo da forma de abordagem e do processamento, podem ser considerados redutores de plasticidade), da serragem e beneficiamento do granito etc. Neste enfoque, alguns pesquisadores advogam que, em verdade, não se está trabalhando necessariamente com vidros ou cerâmicas e, sim, com compósitos em virtude da grande variabilidade na natureza dos materiais envolvidos, enfoque este que não se dará maior aprofundamento, por se tratar de uma questão complexa cujo debate foge ao escopo deste trabalho.

Resíduos com caráter fundente particular são os do processo de fabricação de produtos cerâmicos esmaltados, constituídos basicamente por restos de matérias-primas, peças cruas, produtos acabados fora de especificação e lamas provenientes do tratamento das águas de limpeza (Monfort \& Enrique, 1996) por se situarem na fronteira entre os redutores de plasticidade e fundentes, já que a forma de coleta impede a separação entre esmalte e lamas de esmaltação (fundentes) das peças cruas e queimadas fora de especificação (redutores de plasticidade). Esses resíduos possuem elevado teor de álcalis e somente $10 \%$ deles podem ser tóxicos ou perigosos e, na sua grande maioria, já sofreram as transformações térmicas do processo de queima, podendo ser adicionados em elevadas quantidades na formulação das massas cerâmicas.

A Tabela 2 apresenta propriedades e características cerâmicas de tijolos que contém resíduos fundentes. Com base na Tabela 2, pode-se observar que a quantidade incorporada de resíduos fundentes à formulações cerâmicas, pode atingir facilmente $20 \%$ em massa, o que pode parecer insuficiente, mas é adequado para absorver grande quantidade de resíduos de várias indústrias apenas com a utilização de olarias ou pequenas empresas cerâmicas, situadas em regiões circunvizinhas às metalúrgicas. As propriedades mecânicas ilustradas nessa Tabela, estão dentro da faixa de valores

Tabela 2. Características e propriedades cerâmicas de tijolos com resíduos fundentes*

\begin{tabular}{|c|c|c|c|c|}
\hline \multirow{2}{*}{ Características Cerâmicas } & \multicolumn{4}{|c|}{ Tipo de Resíduo } \\
\hline & Indústria do Aço & Lama de Esmaltação & Hidróxidos de Metal & Resíduos Cerâmicos \\
\hline Teor de resíduo (\%) & 20 & 50 & $2-20$ & 80 \\
\hline Técnica de moldagem & Extrusão & Extrusão & Extrusão & Manual \\
\hline Absorção de água (\%) & $16-18$ & $2-9$ & $0-15$ & $5-18$ \\
\hline Retração de queima (\%) & $<1$ & 9 & $3-9$ & $<1$ \\
\hline Resistência à flexão após queima (MPa) & $8-12$ & $24-31$ & $18-46$ & - \\
\hline
\end{tabular}

* Fonte: Palmonari \& Tenaglia (1985); Domínguez \& Ullmann (1996); Marms et al. (1997) 
observados na literatura para tijolos, apesar de alguns corpos terem sido queimados em temperaturas relativamente baixas (800 a $900{ }^{\circ} \mathrm{C}$ ) o que evidencia o caráter fundente dos resíduos.

Lembra-se que não apenas a produção de peças cerâmicas mais "rústicas" (tijolos, telhas, revestimentos etc) mas também setores de cerâmica fina, podem absorver resíduos fundentes, a exemplo da utilização de rejeitos provenientes da indústria metalúrgica na produção de vidrados cerâmicos, fibras de vidro, ligantes para abrasivos etc (Herman, 1998; Yalçin \& Servinç, 2000).

Neste sentido, tem-se como exemplo a descoberta da possibilidade de utilização do resíduo do processo Bayer processo de produção de alumina - que consiste em uma lama vermelha com elevado teor de sódio, na produção de vidrados para uma série de produtos, ressaltando-se que este rejeito também pode ser utilizado com sucesso na produção de tijolos, sendo a lama o principal problema enfrentado pelas refinarias por ser altamente agressiva ao meio ambiente e de difícil armazenamento, devido ao enorme volume de material produzido diariamente, o que provoca grandes gastos às empresas e potenciais e permanentes riscos de contaminação do solo e de lençóis freáticos.

Por fim, um ponto que merece ser destacado sobre o qual se deve tomar muitas precauções, é a possibilidade de liberação de produtos voláteis durante a queima de resíduos fundentes, que podem ser altamente danosos aos refratários dos fornos cerâmicos e, também, ao meio ambiente, evidenciando a necessidade desses resíduos serem manipulados apenas após terem sido implantadas todas as medidas de segurança necessárias à total garantia da saúde dos operários e da preservação do meio ambiente.

\section{Resíduos combustíveis}

Em geral, os resíduos combustíveis são provenientes de processos industriais que contêm elevado teor de substâncias orgânicas e lhes conferem alto poder calorífico. Esta categoria inclui os resíduos das estações de tratamento de rejeitos urbanos, resíduos da exploração de carvão, resíduos da indústria têxtil e de curtume, resíduos derivados da extração e refino do petróleo e da indústria do papel e madeira.

A utilização de resíduos combustíveis por parte das indústrias cerâmicas pode ser efetuada de duas maneiras: por incorporação dos resíduos à massa cerâmica ou mistura com os combustíveis responsáveis pela queima do corpo cerâmico, sendo que, em ambos os casos, é utilizado o poder calorífico dos resíduos para auxiliar na queima.

O uso de materiais combustíveis como auxiliares de queima pode chegar a propiciar economia energética da ordem dos $45 \%$; todavia, muitos cuidados devem ser tomados ao se fazer uso de resíduos na queima, já que podem liberar vários gases altamente nocivos à saúde humana, sendo altamente recomendado o uso de filtros para gases (existem filtros apenas para particulados) quando utilizar esses resíduos, o que é indispensável, mas, muitas vezes, é ignorado por vários produtores cerâmicos, seja por falta de informações (pequenos produtores) ou falta de responsabilidade ambiental. E é aproveitando o desconhecimento ou a irresponsabilidade de alguns produtores que várias indústrias conseguem eliminar seus resíduos através da queima barata em olarias, indústrias de revestimento e cimento.

A Tabela 3 mostra o conteúdo energético de matériasprimas que podem ser utilizadas no processamento cerâmico. Observa-se que o conteúdo energético dos resíduos é bastante variável; todavia, podem ser utilizados de forma bastante rentável se forem queimados em condições oxidantes, a fim de se ter um máximo rendimento dos combustíveis. Também pode ser utilizada uma mistura de resíduos, para se ter um balanço energético que otimize a queima, sendo este comportamento já muito utilizado por produtores próximos a pólos petroquímicos, onde há abundância de rejeitos do refino do petróleo.

Tabela 3. Conteúdo energético de matérias-primas que podem ser utilizadas pelo processo de queima*

\begin{tabular}{lc}
\hline Tipo de Resíduo & Energia Específica $\left(\mathrm{kcal} \mathrm{kg}^{-1}\right)$ \\
\hline Lamas de lavagem de lã & Variável \\
Lama da indústria do papel & 416 \\
Exaustão de óleos minerais & 1700 \\
Resíduos da indústria têxtil & $4500-7000$ \\
Resíduos da azeitona & 4447 \\
Resíduos da indústria & 2000 \\
$\quad$ de curtumes & $1670-4540$ \\
Serragem de madeira & $7500-7700$ \\
Coque petróleo & $300-1380$ \\
Resíduos da extração & $350-2771$ \\
$\quad$ e tratamento de carvão & 3060 \\
Cinzas & \\
Resíduos da noz de coco & \\
* Fonte: Dondi et al. (1998) &
\end{tabular}

A utilização de rejeitos combustíveis pode ter implicações nas propriedades finais do corpo cerâmico e nas suas características de processamento, à semelhança dos resíduos anteriormente abordados, principalmente quando são incorporados às massas cerâmicas; como exemplo tem-se a utilização de resíduos provenientes do refino do petróleo na fabricação de peças cerâmicas (Amaral \& Domingues, 1991) onde atuam como plastificantes e lubrificantes (além de redutores do consumo de energia) ou a utilização de resíduos combustíveis diversos, a fim de se obter produtos com características de isolamento térmico e/ou acústico, em virtude da porosidade provocada pela volatilização do material.

Neste ponto, é imprescindível evidenciar que a utilização de resíduos combustíveis adicionados às massas cerâmicas pode provocar sensível diminuição da resistência mecânica do corpo, associada à formação de grande quantidade de poros com a volatilização do combustível na queima, e, alterar a composição mineralógica do produto, caso a queima não provoque a adequada oxidação dos resíduos, deixando carbono na massa, o qual pode atuar como agente redutor durante o restante da queima.

Há grande tendência mundial na reciclagem de resíduos com poder calorífico na indústria cerâmica, tendo-se uma vasta gama de trabalhos que abordam essas tecnologias. Citam-se, como exemplo, a utilização de resíduos da indústria do papel e celulose e os das estações de tratamento de rejeitos urbanos (Mesaros, 1989) em virtude do enorme volume desses resíduos 
e do forte impacto ambiental que têm nos recursos hídricos e, por conseguinte, em toda a sociedade.

A Tabela 4 apresenta propriedades e características de tijolos obtidos a partir de formulações com incorporações de resíduos combustíveis, observando-se que a quantidade de resíduos incorporados às formulações é muito dependente do tipo de rejeito, variando de valores inferiores a $10 \%$ a valores em torno de $50 \%$.

No que se refere às características mecânicas, verifica-se que a elevada porosidade (expressa pela absorção de água) conduz a baixos valores de resistência, sendo um fator decisivo no êxito dos produtos em qualquer aplicação cerâmica. Observa-se, ainda, que grande maioria das massas com resíduos apresentou corpos cerâmicos com valores de resistência adequados para a produção de tijolos (resistência $>5 \mathrm{MPa}$ ).

\section{Cinzas volantes e resíduos de incineradores urbanos}

As cinzas volantes e os resíduos oriundos da incineração de rejeitos urbanos; poderiam ser enquadrados em algum dos outros grupos já descritos; todavia em virtude de suas peculiaridades e, principalmente, do grande enfoque mundial que recebem nos últimos anos, em especial na Europa e em alguns países da Ásia, preferiu-se enquadrá-los em um grupo à parte.

A utilização de carvão como combustível em centrais termoelétricas, produz resíduos sólidos, designados cinzas volantes, que chegam a conter $16 \%$ de carbono incombustível e possuem características físico-químicas extremamente diferenciadas em função, sobretudo, do tipo de carvão e de forno utilizados, sendo uma termoelétrica de porte médio responsável por centenas de toneladas de cinzas por ano.

A grande quantidade de pesquisas voltadas para a reciclagem de cinzas volantes está relacionada aos milhões de toneladas de cinzas produzidas pelos países que têm grande parte dos seus sistemas elétricos baseados em centrais termoelétricas. Essas cinzas volantes são correntemente depositadas ou utilizadas como aterro, o que causa um impacto ambiental altamente negativo, em virtude: da potencialidade de lixiviação de substâncias tóxicas para o solo e o lençol freático, da mudança da composição elementar da vegetação que cresce nas circunvizinhanças dos depósitos e do aumento de elementos tóxicos através da cadeia alimentar (Erol et al., 2000).
Atividades industriais pertinentes à utilização de cinzas volantes em artigos economicamente viáveis têm recebido larga popularidade nas últimas décadas em várias áreas, como a produção de cimento e concreto e de tijolos; todavia, a quantidade utilizada de cinzas volantes ainda é muito pequena e, conseqüentemente, novas formas para sua utilização como matéria-prima cerâmica, são pesquisadas (Boccaccini et al. 1997). Uma rota alternativa para o gerenciamento desses resíduos é a sua utilização na produção de vidros, vidroscerâmicos e compósitos. Esta tecnologia será abordada logo em seguida, juntamente com sua aplicação aos resíduos da incineração.

O principal problema nos países desenvolvidos e com elevado adensamento populacional, é a grande quantidade de rejeitos domiciliares gerados a cada dia e que devem ser descartados sem agressões ao meio ambiente. O problema do rejeito pode ser encarado considerando-se a redução das fontes, reciclagem, reutilização, tratamentos e formas de deposição. No presente, a maior parte dos rejeitos é depositada em aterros sanitários, porém esta não é a forma ambientalmente mais correta e melhores estratégias envolvem a reciclagem; no entanto, a reciclagem, que envolve a seleção e a classificação dos resíduos, é apenas adequada para cerca de $50 \%$ do rejeito urbano (sem se levar em consideração o lodo proveniente do tratamento dos esgotos) e, assim, a reciclagem, por si só, não pode solucionar o problema dos rejeitos urbanos (Romero et al., 2000).

A opção complementar à reciclagem e de crescente aceitação em vários países, é a incineração com recuperação de energia, cujos resíduos são incinerados em fornos com filtros adequados para retenção dos gases e particulados, provenientes da queima, e o calor é utilizado para co-geração de energia elétrica e/ ou térmica.

De forma geral, o processo de incineração tem por objetivo, além de gerar energia, reduzir o volume $(\approx 90 \%)$ e massa $(\approx$ $70 \%$ ), dos resíduos a fim de economizar espaço nos aterros, destruir completamente a matéria orgânica, garantido a total desinfecção do resíduo e decomposição dos poluentes inorgânicos (Barbieri et al., 2000a); todavia, o processo gera certa quantidade de resíduos sólidos. Considerando-se um balanço mássico no incinerador, tem-se que, de cada $1000 \mathrm{~kg}$ de resíduo queimado é produzido em torno de $30 \mathrm{~kg}$ de cinza volantes e $300 \mathrm{~kg}$ de particulados mais pesados, do inglês, designados por "bottom ash" (Barbieri et al., 2000b). Por análise

Tabela 4. Características e propriedades cerâmicas de tijolos obtidos a partir de formulações com incorporações de resíduos combustíveis* $^{*}$

\begin{tabular}{|c|c|c|c|c|c|c|c|}
\hline \multirow[b]{2}{*}{ Características Cerâmicas } & \multicolumn{7}{|c|}{ Tipo de Resíduo } \\
\hline & $\begin{array}{l}\text { Indústria } \\
\text { de Papel }\end{array}$ & $\begin{array}{l}\text { Indústria } \\
\text { de Papel }^{* *}\end{array}$ & $\begin{array}{c}\text { Lama } \\
\text { de Esgoto }\end{array}$ & $\begin{array}{c}\text { Lodo } \\
\text { Orgânico }\end{array}$ & $\begin{array}{c}\text { Casca } \\
\text { de Arroz }\end{array}$ & $\begin{array}{c}\text { Cinza } \\
\text { de Carvão }\end{array}$ & Turfa \\
\hline Teor de resíduo (\%) & $1-50$ & $0-15$ & $20-40$ & $13-26$ & $6-10$ & $5-10$ & $0-9$ \\
\hline Temperatura de queima $\left({ }^{\circ} \mathrm{C}\right)$ & 1050 & $850-1050$ & $950-1050$ & 1150 & $800-900$ & $850-1050$ & 950 \\
\hline Absorção de água (\%) & $10-26$ & $2-17$ & $38-40$ & $11-16$ & $17-23$ & $14-26$ & $21-27$ \\
\hline Retração de queima (\%) & $14-22$ & $-0,25-4,40$ & $5-6$ & 11 & 0,1 & 0,3 & $29-33$ \\
\hline
\end{tabular}

* Fonte: Alleman (1989); Mesaros et al. (1989); Neves (2002)

** Lama com elevado teor de sulfato de bário

*** Após queima 
das frações granulométricas do particulado mais pesado, observa-se que o "bottom ash" é constituído essencialmente por materiais vítreos, cerâmicas sintéticas, minerais, pequena quantidade de metais magnéticos e por metais pesados, que se concentram na fração mais fina (Chimenos et al., 1999).

Em virtude das regulamentações que reforçam as medidas de proteção ambiental, há grande interesse em se encontrar opções tecnológicas capazes de converter esses resíduos em novos materiais para o mercado. A tecnologia cerâmica da vitrificação e vitrificação com recristalização controlada, parece ser a solução mais promissora, em virtude de converter resíduos em materiais com boas propriedades tecnológicas a um custo relativamente baixo.

As cinzas volantes, oriundas de termoelétricas e incineradores, bem como os "bottom ash", vêm sendo reutilizados com grande sucesso na forma de matérias-primas para produção de vidros, vidros-cerâmicos e compósitos com matriz vítrea, em virtude principalmente de se poder transformar composições químicas complexas, contendo metais pesados, em produtos não danosos ao meio ambiente. Ademais, em razões da sua forma pulverulenta e pelo montante produzido, é muito mais conveniente à produção de vidros e vitrocerâmicos, que materiais mais comumente utilizados para este fim, como algumas escórias siderúrgicas (Erol et al., 2001).

Em particular, as propriedades que um vidro deve exibir, como bom comportamento de fusão, homogeneidade e durabilidade, estão intimamente relacionadas com sua composição química. Nesta perspectiva, é importante que resíduos de diferentes origens sejam submetidos simultaneamente ao processo de vitrificação, a fim de que cada um possa contribuir com as quantidades apropriadas de agentes vitrificantes $\left(\mathrm{SiO}_{2}, \mathrm{Al}_{2} \mathrm{O}_{3}, \ldots\right)$, fundentes $\left(\mathrm{Na}_{2} \mathrm{O}, \mathrm{K}_{2} \mathrm{O}, \ldots\right)$ e estabilizadores $(\mathrm{CaO}, \mathrm{MgO}, \mathrm{ZnO}, \mathrm{PbO}, \ldots)$ para que sejam obtidas características físico-químicas adequadas no produto final.

O processo de vitrificação simula o que realmente ocorre na natureza: vidros naturais produzidos por erupções vulcânicas são basicamente materiais inertes, mesmo quando contêm elementos tóxicos, em virtude de estarem imersos em uma matriz vítrea extremamente estável. Similarmente, os vidros produzidos com resíduos também são muito estáveis às agressões ambientais, não liberando quantidades significativas de elementos tóxicos, cujas quantidades são liberadas infinitesimalmente inferiores às liberadas quando o resíduo não está vitrificado ou imerso em matriz vítrea (Barbieri et al., 2000a).

$\mathrm{Na}$ Tabela 5 tem-se alguns resultados da literatura que reforçam o que foi abordado antes, evidenciando a resistência dos vidros e vidros-cerâmicos, no que se refere à lixiviação de metais pesados. Pode-se observar que todos os resultados se apresentam abaixo dos limites da NBR 10006 (ABNT, 1987) o que é extremamente satisfatório e destaca a imobilização que este tipo de tratamento possibilita, justificando o montante de pesquisas, principalmente na Europa, que se têm dedicado ao desenvolvimento de vidros e vitrocerâmicos a partir de composições contendo resíduos altamente tóxicos.

Tabela 5. Resultados de ensaios de lixiviação ${ }^{1}$ em vidros e vitrocerâmicos obtidos a partir de formulações contendo resíduos ${ }^{2}$

\begin{tabular}{|c|c|c|c|c|c|c|c|c|c|c|c|c|}
\hline \multirow{2}{*}{ Resíduos } & \multirow{2}{*}{ Material } & \multicolumn{11}{|c|}{ Teor de Elementos no Líquido após Ensaio de Lixiviação (mg L $\left.{ }^{-1}\right)$} \\
\hline & & $\mathrm{Ba}$ & $\mathrm{Cd}$ & $\mathrm{Pb}$ & $\mathrm{Cr}$ & $\mathrm{Al}$ & $\mathrm{Fe}$ & $\mathrm{Cu}$ & $\mathrm{Zn}$ & Mo & Co & V \\
\hline Siderurgia & Vitrocerâmico & 0,340 & $\mathrm{ND}^{4}$ & ND & 0,086 & - & - & - & - & - & - & - \\
\hline Cinza volante & $\begin{array}{c}\text { Vidro } \\
\text { Natural }^{3}\end{array}$ & $\begin{array}{l}- \\
-\end{array}$ & $\begin{array}{c}\text { ND } \\
25,49\end{array}$ & $\begin{array}{l}0,059 \\
9,740\end{array}$ & $\begin{array}{l}0,004 \\
0,030\end{array}$ & $\begin{array}{l}- \\
-\end{array}$ & $\begin{array}{l}- \\
-\end{array}$ & $\begin{array}{l}0,025 \\
24,02\end{array}$ & $\begin{array}{l}1,594 \\
62,10\end{array}$ & $\begin{array}{l}- \\
-\end{array}$ & $\begin{array}{l}- \\
-\end{array}$ & $\begin{array}{l}- \\
-\end{array}$ \\
\hline $\begin{array}{l}\text { Cinza volante } \\
\text { Radioativo }\end{array}$ & Vidro & 6,700 & 0,020 & 0,020 & $<0,01$ & - & - & - & 0,89 & - & - & - \\
\hline Metalurgia & $\begin{array}{l}\text { Vidro } \\
\text { Vitrocerâmico }\end{array}$ & - & 0,002 & 0,492 & - & 0,370 & 0,675 & 0,092 & 0,480 & - & - & - \\
\hline $\begin{array}{l}\text { Siderurgia } \\
\text { Cinza volante } \\
\text { Vidro }\end{array}$ & $\begin{array}{c}\text { Vidro } \\
\text { Vidro } \\
\text { Vidro } \\
\text { Vidro } \\
\text { Vidro } \\
\text { Vidro }\end{array}$ & $\begin{array}{l}- \\
- \\
- \\
- \\
-\end{array}$ & $\begin{array}{c}\text { ND } \\
\text { ND- } \\
0,005 \\
\text { ND } \\
0,001 \\
\text { ND }\end{array}$ & $\begin{array}{c}0,040 \\
0,100 \\
0,006 \\
0,004 \\
\text { ND } \\
0,170\end{array}$ & $\begin{array}{l}- \\
- \\
- \\
- \\
- \\
-\end{array}$ & $\begin{array}{c}0,100 \\
\text { ND } \\
0,060 \\
0,030 \\
0,090 \\
0,160\end{array}$ & $\begin{array}{c}0,060 \\
0,070 \\
0,050 \\
0,030 \\
\text { ND } \\
0,050\end{array}$ & $\begin{array}{l}0,030 \\
0,033 \\
0,008 \\
0,011 \\
0,016 \\
0,001\end{array}$ & $\begin{array}{c}0,018 \\
0,016 \\
\text { ND } \\
0,118 \\
\text { ND } \\
\text { ND }\end{array}$ & $\begin{array}{l}- \\
- \\
- \\
- \\
- \\
-\end{array}$ & $\begin{array}{l}- \\
- \\
- \\
- \\
- \\
-\end{array}$ & $\begin{array}{l}- \\
- \\
- \\
- \\
-\end{array}$ \\
\hline Catalisadores & $\begin{array}{l}\text { Vitrocerâmico } \\
\text { Natural }^{3}\end{array}$ & $\begin{array}{l}- \\
-\end{array}$ & - & $\begin{array}{l}- \\
-\end{array}$ & $\begin{array}{l}- \\
-\end{array}$ & $\begin{array}{l}- \\
-\end{array}$ & - & $\begin{array}{l}- \\
-\end{array}$ & $\begin{array}{l}- \\
-\end{array}$ & $\begin{array}{l}0,050 \\
42,50\end{array}$ & $\begin{array}{l}0,020 \\
44,00\end{array}$ & $\begin{array}{l}\mathrm{ND}^{\#} \\
0,200\end{array}$ \\
\hline & $\begin{array}{l}\text { Vidro } \\
\text { Vidro }\end{array}$ & $\begin{array}{l}- \\
-\end{array}$ & $\begin{array}{l}\text { ND } \\
\text { ND }\end{array}$ & $\begin{array}{l}0,002 \\
0,005\end{array}$ & $\begin{array}{c}<0,01 \\
0,011\end{array}$ & $\begin{array}{l}0,003 \\
0,005\end{array}$ & $\begin{array}{l}0,004 \\
0,405\end{array}$ & $\begin{array}{l}0,023 \\
0,027\end{array}$ & $\begin{array}{l}0,095 \\
0,170\end{array}$ & $\begin{array}{l}- \\
-\end{array}$ & $\begin{array}{l}- \\
-\end{array}$ & $\begin{array}{l}- \\
-\end{array}$ \\
\hline Metalurgia & Vidro & - & ND & $<0,01$ & $<0,01$ & $<0,01$ & 0,080 & $<0,01$ & 0,170 & - & - & - \\
\hline Esgotos & Vidro & - & ND & 0,020 & $<0,01$ & 1,090 & 0,630 & $<0,01$ & 3,300 & - & - & - \\
\hline Granito & $\begin{array}{l}\text { Vidro } \\
\text { Vidro } \\
\text { Vidro }\end{array}$ & $\begin{array}{l}- \\
- \\
-\end{array}$ & $\begin{array}{l}\text { ND } \\
<0,01 \\
<0,01\end{array}$ & $\begin{array}{l}0,001 \\
0,060 \\
0,104\end{array}$ & $\begin{array}{l}\text { ND } \\
\text { ND } \\
\text { ND }\end{array}$ & $\begin{array}{l}0,001 \\
0,051 \\
0,074\end{array}$ & $\begin{array}{l}<0,01 \\
0,020 \\
0,030\end{array}$ & $\begin{array}{l}<0,01 \\
<0,01 \\
<0,01\end{array}$ & $\begin{array}{l}<0,01 \\
0,009 \\
0,014\end{array}$ & $\begin{array}{l}- \\
- \\
-\end{array}$ & $\begin{array}{l}- \\
- \\
-\end{array}$ & $\begin{array}{l}- \\
-\end{array}$ \\
\hline $\begin{array}{l}\text { Máximo no Brasi } \\
\text { Máximo na Itália }\end{array}$ & $\frac{\left.\mathrm{mg} \mathrm{L}^{-1}\right)}{\left.\mathrm{ng} \mathrm{L}^{-1}\right)}$ & $\begin{array}{c}100,0 \\
20,0\end{array}$ & $\begin{array}{c}0,5 \\
0,02\end{array}$ & $\begin{array}{l}5,0 \\
0,2\end{array}$ & $\begin{array}{l}5,0 \\
0,2\end{array}$ & $\begin{array}{c}\mathrm{NR}^{5} \\
1,0\end{array}$ & $\begin{array}{l}\text { NR } \\
2,0\end{array}$ & $\begin{array}{l}\mathrm{NR} \\
0,1\end{array}$ & $\begin{array}{l}\mathrm{NR} \\
0,5\end{array}$ & $\begin{array}{l}\text { NR } \\
7,0\end{array}$ & $\begin{array}{l}\text { NR } \\
0,07\end{array}$ & $\begin{array}{c}\mathrm{NR} \\
0,70\end{array}$ \\
\hline
\end{tabular}


Assim objetivando desenvolver materiais altamente resistentes às condições ambientais e obter produtos com características comerciais, vários estudos têm-se detido à análise do comportamento de vitrificação de formulações obtidas pela mistura de vários tipos de resíduos (indústria metalúrgica, da mineração, do vidro etc.) com cinzas volantes. Relembra-se que, por vezes, faz-se oportuna a adição de matérias-primas convencionais às formulações (Mishra et al., 2000; Crespo \& Rincón, 2001).

A Tabela 6 apresenta, a título de ilustração, as propriedades de vidros e vitrocerâmicos obtidos a partir de composições contendo cinzas volantes (ou "bottom ash") e outros tipos de resíduos. Observa-se que os valores das propriedades dos vidros obtidos a partir de resíduos, estão de acordo com valores referentes a composições comerciais de vidros de sílica mais comumente usados, e que os vitrocerâmicos formulados a partir de resíduos também apresentam características semelhantes a produtos comerciais, o que ressalta o êxito na utilização de resíduos no desenvolvimento de vidros e vitrocerâmicos semelhantes aos obtidos comercialmente.

Tabela 6. Propriedades de vidros e vidros-cerâmicos obtidos a partir de resíduos*

\begin{tabular}{lcc}
\hline Propriedades Características & Contendo Resíduos & Comerciais \\
\hline $\begin{array}{l}\text { Vidro } \\
\text { Módulo de young (GPa) }\end{array}$ & $90-121$ & $72-69$ \\
$\begin{array}{l}\text { Dureza vickers (GPa) } \\
\text { Tenacidade à fratura } \\
\left(\mathrm{K}_{\mathrm{IC}}\right)\left(\mathrm{MPa} \mathrm{m} \mathrm{m}^{1 / 2}\right)\end{array}$ & $4,0-6,0$ & $4,0-5,0$ \\
$\begin{array}{c}\text { Coeficiente de expansão } \\
\text { térmica }\left(10^{-6} \mathrm{~K}^{-1}\right)\end{array}$ & $0,5-0,9$ & $0,7-0,8$ \\
\hline $\begin{array}{l}\text { Vitrocerämico } \\
\text { Módulo de young }(\mathrm{GPa})\end{array}$ & $5,9-10,7$ & $0,5-9,0$ \\
$\begin{array}{l}\text { Dureza vickers }(\mathrm{GPa}) \\
\text { Tenacidade à fratura } \\
\quad\left(\mathrm{K}_{\mathrm{IC}}\right)\left(\mathrm{MPa} \mathrm{m} \mathrm{m}^{1 / 2}\right)\end{array}$ & $5,5-134$ & $85-135$ \\
$\begin{array}{l}\text { Coeficiente de expansão } \\
\text { térmica }\left(10^{-6} \mathrm{~K}^{-1}\right)\end{array}$ & $0,6-1,7$ & - \\
* Fonte: Boccaccini et al. (1995), Romero et al. (2000), Park \& Heo (2001), Ferraris et al., (2001)
\end{tabular}

No que se refere aos compósitos, é interessante mencionar que são particularmente importantes quando se trabalha conjuntamente com resíduos metalúrgicos e de extração mineral constituídos, basicamente, por óxidos metálicos não adequados à vitrificação, já que a combinação com cinzas volantes pode proporcionar a obtenção de materiais compostos por matriz vítrea, que impedem a lixiviação dos metais e, ao mesmo tempo, possuem aplicações tecnológicas, sem perigos ao meio ambiente havendo nesses casos, uma real caracterização do material como compósito.

\section{Resíduos radioativos}

Os resíduos radioativos não são necessariamente considerados matérias-primas cerâmicas, a não ser que se esteja trabalhando com materiais nucleares; todavia, esses resíduos são, há muito tempo, incorporados aos materiais cerâmicos, a fim de se poder armazená-los de forma mais segura, enquadrando-se então como resíduo absorvido pela indústria cerâmica.

O gerenciamento de resíduos radioativos envolve uma série de problemas, sendo desenvolvidos numerosos processos de tratamentos para se poder manipular esses resíduos com mais segurança. Independentemente do tratamento, uma questão é sempre preponderante, que é a conversão dos resíduos a uma forma altamente estável, sejam eles resíduos de baixo nível de radioatividade, resíduos transurânicos, restos de plutônio, resíduos de combustível nuclear etc (Forsberg et al., 1996).

Para se armazenar, por longos períodos de tempo, resíduos nucleares, o que é uma necessidade cada dia maior, é necessário o desenvolvimento de materiais quimicamente estáveis a fim de se evitar possíveis lixiviações ou dispersão dos elementos, por mais ínfima que aparente ser, e manter seu isolamento até decaírem de resíduos radioativos a não radioativos.

As formas que em geral se utilizam para deposição permanente de resíduos radioativos, incluem principalmente os vidros de borosilicatos (Hess et al., 1998) e alguns tipos específicos de cerâmicas cristalinas, que geralmente envolvem fosfatos e zircônia, sendo esta preferência relacionada à performance desses materiais e a capacidade de absorverem, em sua estrutura, vários tipos de elementos simultaneamente, o que minimiza a necessidade de separar elementos específicos do resíduo bruto, antes de submetê-lo ao processo de vitrificação. Muitos estudos (Lin \& Shen, 1996; Raman, 2000; Bois et al., 2001) têm-se dedicado ao desenvolvimento de materiais cerâmicos capazes de incorporar resíduos radioativos, sejam eles na forma vítrea ou cristalina, havendo sempre enfoque na capacidade de imobilização desses resíduos e na estabilidade desses materiais com o tempo, já que estão submetidos a uma fonte de radiação, o que decresce a durabilidade e estabilidade do material (Ezz-Eldin, 2001).

\section{ANÁLISE CRÍTICA}

Com o intuito de propiciar uma visão crítica do enfoque apresentado anteriormente e evidenciar alguns pontos que se acredita merecerem evidência, são abordados, a seguir, alguns destaques sobre a utilização de resíduos na indústria cerâmica.

A grande maioria das pesquisas que objetivam a utilização da indústria cerâmica como opção de reaproveitamento ou simplesmente de absorção de resíduos industriais e urbanos, está centrada a grande maioria no continente europeu e em alguns países asiáticos (Japão, Korea do Sul, Taiwan) havendo um grande crescimento no número de instituições de pesquisas européias que se vêm dedicando a este tema nos últimos anos.

A participação da Europa na vanguarda dos estudos sobre incorporação de resíduos na indústria cerâmica, pode ser creditada basicamente a dois fatores: primeiro, a uma questão de maior esclarecimento dos seus técnicos sobre a questão ambiental, o que aliado à sua responsabilidade social apurada, pressiona os organismos governamentais a atuarem de forma rígida e severa, no que se refere à preservação do meio ambiente, com a adoção de medidas que impõem, às empresas e órgãos públicos, a responsabilidade de conservação do patrimônio natural; segundo, é devido ao grande centro produtor de cerâmica tradicional que existe na Europa (com destaque para países como Espanha, Itália, Turquia etc) que, em virtude da 
escassez e do elevado custo das matérias-primas e ao fato de que grande variedade de resíduos possui composições químicas que possibilitam seu uso na indústria cerâmica (principalmente no que se refere às cerâmicas tradicionais), incentiva várias entidades de pesquisa a buscarem alternativas para a grande dependência dos produtores com os seus fornecedores de matérias-primas.

Assim como, base em estímulos sociais e econômicos, a Europa "lidera" a tecnologia de incorporação de resíduos à indústria cerâmica, sendo seu exemplo seguido rapidamente por alguns países asiáticos, que também possuem certo destaque nessa tecnologia, principalmente no que diz respeito aos resíduos de incineradores de resíduos urbanos.

Neste contexto, é sentida a ausência de uma contribuição maior dos EUA no desenvolvimento de tecnologias para reutilização de resíduos seja no que se refere à incorporação na indústria cerâmica ou a qualquer outro tipo de tecnologia. Isto é especialmente grave, já que os EUA possuem capacidade de pesquisa e desenvolvimento, que é referência mundial em praticamente todas as áreas e também porque sua capacidade poluidora é, sem dúvida, uma das maiores, se não a maior, do mundo. A argumentação de que o uso de resíduos se volta basicamente para a indústria de cerâmica tradicional e que os EUA não possuem suficiente "know how" nesse setor, não é justificada, já que vários estudos, em particular os que compõem a vanguarda da reutilização de resíduos, ressaltam a possibilidade de uso de resíduos industriais e urbanos no desenvolvimento de cerâmicas de alto desempenho, com destaque para os vitrocerâmicos.

A participação do Brasil no contexto mundial ainda é muito pequena, o que aparenta que os pesquisadores brasileiros não se dedicam ao estudo desse tema, o que não é verdade, já que vários pesquisadores se têm dedicado à pesquisa e ao desenvolvimento de tecnologias de reciclagem (reutilização) de rejeitos, principalmente através de sua incorporação na indústria cerâmica, apesar de que o volume de pesquisas ainda é muito pequeno, se comparado à quantidade de resíduos produzidos no Brasil.

Esse aparente descaso dos pesquisadores com o tema, está relacionado à pequena divulgação dos trabalhos nacionais em periódicos e congressos internacionais, sendo centralizada de forma quase que total em periódicos e congressos nacionais. Não que a publicação e a valorização dos eventos e revistas nacionais não sejam válidos; pelo contrário, são essas contribuições que enriquecem a tecnologia e a ciência nacional, mas no mundo atual se faz necessária uma integração cada vez maior entre os pesquisadores de todos os continentes. Ademais, se os pesquisadores brasileiros não se dedicarem bem mais à exposição de seus estudos em nível internacional, estarão se arriscando a, em um futuro próximo, serem "taxados" pela comunidade científica de meros "copiadores" de tecnologia, já que várias pesquisas são desenvolvidas simultaneamente em todo o mundo, abordando problemas comuns a vários países, tendo uma exposição contínua de seus resultados em níveis internacionais.

No que se refere aos tipos de resíduos mais estudados e às perspectivas da tecnologia da incorporação de resíduos na indústria cerâmica, evidencia-se que as cinzas volantes e os resíduos da incineração de rejeitos urbanos são a nova fronteira no desenvolvimento de novas tecnologias, tal como a tecnologia de vidros e vitrocerâmicos, que adquirem, a cada dia, mais destaque, por utilizarem vários resíduos no desenvolvimento de produtos com alto desempenho. Apesar de já abordados, nesses tópicos não se mencionou que o Brasil é um grande produtor em potencial de cinzas volantes e resíduos de incineração, já que há grande possibilidade de seu sistema de geração de energia elétrica passar a ser composto por um número maior de geradoras termoelétricas (mesmo sendo a maioria baseada na queima de gás natural). A necessidade da rápida construção de novas estações geradoras de energia elétrica e, também, porque os grandes centros urbanos possuem cada vez menos alternativas e espaços para a deposição da crescente quantidade de rejeitos urbanos, o que indica que, dentre em breve, as medidas já adotadas em vários outros países serão adotadas também no Brasil, com a incineração de grande parte dos rejeitos urbanos, principalmente nas maiores áreas metropolitanas.

Outro ponto que merece destaque é a necessidade de conscientização do empresariado brasileiro, de que rejeitos industriais (e aqueles da incineração de rejeitos urbanos) são uma alternativa altamente rentável às matérias-primas cerâmicas convencionais, o que já é muito bem assimilado em várias partes do mundo, mas que no Brasil praticamente inexiste. Grande quantidade de empresários (bem como de engenheiros e técnicos) acredita que a adição de resíduos em formulações utilizadas vão apenas provocar redução nas características mecânicas do produto e uma série de inconvenientes, o que não é de todo errado, mas que pode ser totalmente evitado, caso sejam feitos estudos prévios para otimizar a composição cerâmica, a fim de se manter as características dos produtos e um ciclo de produção semelhante ao das formulações convencionais.

Alguns empresários utilizam resíduos em suas composições, mas sob o aspecto errôneo de que, se forem utilizados materiais de baixo custo, se obterá redução nos custos finais, mesmo com a confecção de produtos de qualidade inferior, não sendo assim abordada a ótica de que os resíduos são hoje uma nova e concreta alternativa às matérias-primas (principalmente nas regiões com grande concentração industrial) e que sua utilização, além de propiciar redução de custos, pode conduzir a produção de peças com características diferenciadas e até mesmo desempenho e aceitação no mercado maior que os produtos fabricados a partir de matérias-primas convencionais.

Um outro segmento que deve ser evidenciado é a esfera governamental, já que tem papel decisivo na reutilização de rejeitos (independentemente de ser ou não na indústria cerâmica) através da imposição de normas severas e fiscalização rígida que impeçam a poluição do meio ambiente e imponham, aos agentes poluidores a responsabilidade de reciclagem ou reutilização de seus resíduos, sendo esta uma das causas mais comuns de desenvolvimento de pesquisas que objetivam soluções alternativas para o problema dos rejeitos.

No Brasil, este fator é ainda mais preponderante, já que grande parte das pesquisas é patrocinada pelo poder público 
necessitando, desta forma, que os órgãos de fomento visualizem a importância da indústria cerâmica como grande fonte sorvedora em potencial de resíduos, bem como as várias vantagens existentes na utilização de resíduos como matériasprimas cerâmicas alternativas, para que pesquisadores possam desenvolver pesquisas com condições e estrutura necessárias a um rápido e bem sucedido desfecho.

\section{CONCLUSÕES}

O estado da arte sobre as possibilidades de utilização dos resíduos industriais e urbanos na indústria cerâmica como matéria-prima alternativa, nos permite concluir-se que:

1. A indústria cerâmica tem elevada capacidade de absorção de resíduos, sejam eles industriais ou urbanos, em virtude do seu volume de produção.

2. A indústria cerâmica possui destaque na reciclagem de resíduos devido à sua capacidade de neutralizar e estabilizar vários resíduos tóxicos.

3. A vanguarda da incorporação de resíduos à industria cerâmica é o desenvolvimento de vidros e vitrocerâmicos.

4. A grande maioria dos estudos voltados para incorporação de resíduos na indústria cerâmica, centraliza-se na Europa e em alguns países asiáticos.

5. Fazem-se necessários mais estudos para que se reciclem, de forma mais acentuada, os resíduos industriais e urbanos no Brasil e que os pesquisadores brasileiros divulguem mais intensamente suas pesquisas em níveis internacionais.

6. É necessária uma conscientização maior de empresários sobre a potencialidade de utilização de rejeitos como matériasprimas cerâmicas alternativas.

7. É que os órgãos de fomento têm papel fundamental no estímulo ao desenvolvimento de tecnologias de reaproveitamento de resíduos.

\section{LITERATURA CITADA}

ABNT-Associação Brasileira de Normas Técnicas, NBR 10 006, Ensaio de lixiviação, Rio de Janeiro, 1987.2p

Alleman, J.E. Beneficial use of sludge in building components - Full-scale production of sludge-amended brick. Interbrick, Freiburg, v.5, n.11, p.28-32, 1989.

Amaral, S.P.; Domingues, G.H. Oily wastes application in ceramic materials manufacturing. Water Science and Tecnology, London, v.24, n.12, p.165-176, 1991.

Barbieri, L.; Corradi, A.; Lancelloti, I. Alkaline and alkalineearth silicate glasses and glas-ceramics from municipal and industrial wastes, Journal of the European Ceramic Society, Amsterdam, v.20, p.2477-2483, 2000a.

Barbieri, L.; Corradi, A.; Lancelloti, I. Bulk and sintered glassceramics by recycling of municipal incinerator bottom ash. Journal of the European Ceramic Society, Amsterdam, v.20, p.1637-1643, 2000b.

Boccaccini, A.R.; Bücker, M.; Bosser, L. Marzalek, K. Glass matrix composites from coal fly ash and waste glass. Journal of the European Ceramic Society, Amsterdam, v.17, p.39-45, 1997.
Boccaccini, A.R.; Köpf, M.; Stumpfe, W. Glass-ceramic from filter dust from waste incinerators. Ceramics International, Oxford, v.21, p.231-235, 1995.

Bois, L.; Guittet, M.J.; Carrot, F.; Trocellier, P; Gautier-Soyer, M. Preliminary results on the leaching process of phosphate ceramics, potential hosts for actinide immobilization. Journal of Nuclear Materials, Amsterdam, v.297, p.129-137, 2001.

Chimenos, J.M.; Segarra, M.; Fernández, M.A.; Espiell, F. Characterization of the bottom ash in municipal solid waste incinerator. Journal of Hazardous Materials A, Amsterdam, v.64, p.211-222, 1999.

Crespo, M.S.H.; Rincón, J.M. New porcelainized stoneware materials obtained by recycling of MSW incinerator fly ashes and granite sawing residues. Ceramics International, Oxford, v.27, p.713-720, 2001.

Domínguez, E.A.; Ullmann, R. "Ecological bricks" made with clay and steel dust pollutants. Applied Clay Science. Amsterdam, v.11, n.2-4, p.237-249, 1996.

Dondi, M.; Fabbri, B; Marsigli, M. Resenha das experiências de reciclagem de resíduos industriais e urbanos na produção de tijolos. Cerâmica Informação, Faenza, v.1, n.1, p.17-30, 1998.

Elwan, M.M.; Hassan, M.S. Recycling of some Egyptian industrial solid wastes in clay bricks. Industrial Ceramics, Faenza, v.18, n.1, p.1-6, 1998.

Erol, M.; Genç, A.; Övecoglu, M.L.; Yücelen, E.; Kücükbayrak, S.; Taptik, Y. Characterization of a glass-ceramic produced from thermal power plant fly ash. Journal of the European Ceramic Society, Amsterdam, v.20, p.2209-2214, 2000.

Erol, M.; Kücükbayrak, S.; Ersoy-Mericboyu, A.; Övecoglu, M.L. Crystallization behavior of glasses produced from fly ash. Journal of the European Ceramic Society, Amsterdam, v.21, p.2835-2841, 2001.

Ezz-Eldin, F.M. Leaching and mechanical properties of cabal glasses developed as matrices for immobilization high-level wastes. Nuclear Instruments and Methods in Physics Research B, Amsterdam, v.183, p.285-300, 2001.

Ferraris, M.; Salvo, M.; Smeacetto, F.; Augier, L.; Barbieri, L.; Corradi, A.; Lancelloti, I. Glass matrix composites from solid waste materials. Journal of the European Ceramic Society, Amsterdam, v.21, p.453-460, 2001.

Forsberg, C.W.; Beahm, E.C.; Parker, G.W.; Elam, K.R. Conversion of radioactive and hazardous chemical wastes into borosilicate glass using the glass material oxidation and dissolution system. Waste Management, Oxford, v.16, n.7, p.621-623, 1996.

Freire, A.S.; Motta, J.F. Potencialidades para aproveitamento econômico do rejeito da serragem do granito. Rochas de Qualidade, São Paulo, v.16, n.123, p.98-108, 1995.

Gualtieri, A.F.; Tartaglia, A. Thermal decomposition of asbestos and recycling in traditional ceramics. Journal of the European Ceramic Society, Amsterdam, v.20, p.1409-1418, 2000.

Herman, D. Glass and glass-ceramic binder obtained from waste material for binding alundum abrasive grains into grinding wheels. Ceramics International, Oxford, v.24, p.515-520, 1998. 
Hess, N.J.; Weber, W.J.; Conradson, S.D.; X-ray absorption fine structure of aged, $\mathrm{Pu}$ doped glass and ceramic waste forms. Journal of Nuclear Materials, Amsterdam, v.254, p.175$184,1998$.

Lin, J.S.; Shen, $\mathrm{P}$ Fabrication of $\mathrm{Ca}_{0}-\mathrm{ZrO}_{2}-\mathrm{TiO}_{2}-\mathrm{Al}_{2} \mathrm{O}_{3}-\mathrm{B}_{2} \mathrm{O}_{3}-\mathrm{SiO}_{2}$ glasses and glass-ceramics - I. Journal of Non-Crystalline Solids, Amsterdam, v.204, p.135-140, 1996.

Marms, W.; Sclmeider, H.; Eichler, W. Potentialities for the utilization of metal hydroxide slurry for masonry brick production. Ziegelindustrie Int, Innsbruck, n.3, p.110-126, 1997.

Mesaros, R.; Use of sludge from the municipal sewage system to brick-making, New life for an obsolescent brickwork. Ziegelindustrie Int., Innsbruck, v.5, p.251-254, 1989.

Mishra, S.C.; Rout, K.C.; Padmanabhan, P.V.A.; Mills, B. Plasma spray coatings of fly ash mixed with aluminium powder deposited on metal substrates. Journal of Materials Processing Technology, Lausanne, v.102, p.9-13, 2000.

Monfort, E.; Enrique, J. E. Economia energética e vantagens meio ambientais da reutilização de resíduos. Cerâmica Industrial, São Paulo, v.1, n.4-5, p.14-20, 1996.

Montano, L.; Bianchini, N.; Rincón, J.M.; Romero, M. Sintering behavior of pressed red wastes from zinc hydrometallurgy. Ceramics International, Oxford, v.27, p.29-37, 2001.

Neves, G. A. Reciclagem de resíduos da serragem de granito para uso como matéria-prima cerâmica. Campina Grande: UFPB, 2002, 252p. Tese Doutorado

Neves, G.A.; Patríco S.M.R.; Ferreira H.C. Utilização de resíduos da serragem de granito para confecção de tijolos cerâmicos. Interação, Campina Grande, v.1, p.3-8, 2000.

Palmonari, C.; Tenaglia, E. Manufactory of heavy-clay products with addition of residual sludge from other ceramic industries. Mineral Petrografia. Acta, London, v.29/A, p.547, 1985.

Park, Y.J.; Heo, J. Vitrification of fly ash from municipal solid waste incinerator. Journal of Hazardous Materials, Amsterdam, v. 2783, p.1-11, 2001.

Pelino, M. Recycling of zinc-hydrometallurgy wastes in glass and glass-ceramic materials. Waste Management, Amsterdam, v.20, p.561-568, 2000.
Pisciella, P.; Crisucci, S.; Karamanov, A.; Pelino, M. Chemical durability of glasses obtained by vitrification of industrial wastes, Wastes Management, Amsterdam, v. 21, p.1-9, 2001.

Raigón, P.M.; Garcia, R.G.; Sánchez, S.P.J. Characterization of waste washing solid product of mining granitic tin-bearing sands and its application as ceramic raw material. Resouces, Conservation and Recycling, Amsterdam, v.17, n.2, p.109124, 1996.

Raman, S.V. Properties of metal phosphates and phosphides in glass-ceramic waste forms. Journal of Non-Crystalline Solids, Amsterdam, v.263-264, p.395-408, 2000.

Romero, M.; Rawlings, R.D.; Rincón, J.M.; Crystal nucleation and growth in glasses from inorganic wastes from urban incineration. Journal of Non-Crystalline Solids, Amsterdam, v. 271, p.106-118, 2000.

Sabrah, B.A.; Ebied, E.A. Utilization of cement-dust as a substitute of some clay content in clay-sand. Interbrick, Freiburg, v.1, p.5129-5137, 1987.

Sheng, J. Vitrification of borate from nuclear power plant using coal fly ash (II) - Leaching behavior of the FA30 glass. Fuel, Oxford, v.81, p.253-256, 2002.

Sun, D.D.; Tay, J.H.; Cheong, H.K.; Leung, D.L.K.; Qian, G. Recovery of heavy metals and stabilization of spent hydrotreating catalyst using a glass-ceramic matrix. Journal of Hazardous Materials B, Amsterdam, v.87, p.213-223, 2001.

Vieira, M.T.; Catarino, L.; Oliveira, M.; Souza, J.; Torralba, J.M.; Cambronero, L.E.G.; Mesones, F.L.G.; Victoria, A. Optimization of the sintering process of raw materials wastes. Journal of Materials Processing Technology, Lausanne, v.92-93, p.97-101, 1999.

Wender, A.A.; Baldo, B.B. O potencial da utilização de um resíduo argiloso na fabricação de revestimento cerâmico - Parte II. Cerâmica Industrial, São Paulo, v.3, n.1-2, p.34-36, 1998.

Yalçin, N.; Servinç, V.; Utilization of bauxite waste in ceramic glazes. Ceramics International, Oxford, v.26, p.485-493, 2000. 